\title{
Nuestra imagen pública desde la neurociencia social
}

\author{
Marisela Romero Vázquez
}

\section{Resumen}

Se aborda la manera en que la imagen pública se relaciona con los procesos que, a partir de su proyección, se llevan a cabo en el cerebro. Es un análisis que se hace con el fin de revelar que la gestión de la imagen pública tiene que ver con temas como la toma de decisiones, la reputación y la neurociencia social, más que con los de índole banal o superficial.

Palabras clave: imagen pública, imagen personal, reputación, neurociencia social, comunicación no verbal.

\section{OUR PUBLIC IMAGE FROM SOCIAL NEUROSCIENCE}

\section{Abstract}

We address how public image relates to the processes that, from its projection, take place in the brain. This analysis is made in order to reveal that public image management has to do with issues such as decision-making, reputation and social neuroscience, rather than with those of banal or superficial nature.

Keywords: public image, personal image, reputation, social neuroscience, non-verbal communication. 


\section{Marisela Romero Vázquez}

marisela.alesiram@gmail.com

https://orcid.org/0000-0002-0078-7400

Egresada de la Licenciatura en Bibliotecología de la Facultad de Filosofía y Letras, de la Universidad Nacional Autónoma de México (UNAM). Con estudios de maestría en la misma profesión. Es maestra en Ingeniería en Imagen Pública y doctora en Imagen Pública (Beca Víctor Gordoa) por el Colegio de Consultores en Imagen Pública.

En el Colegio de Bibliotecología de la Facultad de Filosofía y Letras de la unam, propusó e imparte desde el 2015 las materias: Branding para el Bibliotecólogo y desde el 2019, Storytelling para el Bibliotecólogo. Algunos de sus temas en conferencias, cursos y talleres son: branding, personal branding, storytelling, imagen de marca personal, percepción, persuasión, comunicación no verbal, brechas de marca personal, arquetipos, empoderamiento de la mujer, lectura en voz alta; entre otros. Como consultora independiente de imagen pública, actualmente dicta conferencias, imparte talleres y cursos, y es autora de capítulos de libros asociados con su labor como bibliotecóloga y de artículos académicos vinculados con la imagen pública. 


\section{Introducción}

Corría el año 48 a. C., cuando Julio César tuvo un encuentro más que mágico con una mujer que envuelta en un tapete emergió, como Venus, de entre las olas para aparecer semidesnuda ante sus ojos y los de sus generales. La joven Cleopatra impactó a todos, pero más a Julio César, quien, fascinado con su imagen, buscó pretextos para permanecer a su lado. Cuando el estratega romano murió, su lugar fue ocupado por Marco Antonio, quien también cayó bajo el hechizo de Cleopatra.

¿Era la belleza física lo que atraía a los hombres hacia la imagen de Cleopatra? ¿Cuál era la pócima que encantaba a sus amantes? En Alejandría había mujeres mucho más hermosas que ella, lo que Cleopatra poseía era una habilidad personal para dejar, de manera constante, una diversidad de imágenes mentales en quienes la rodeaban: "ofrecía tributos, batallas simuladas, expediciones, orgiásticos bailes de máscaras. Todo tenía un toque dramático y se llevaba a cabo con inmensa energía. Para el momento en que sus amantes posaban su cabeza junto a ella en la almohada, su mente era un torbellino de sueños e imágenes" (Greene, 2001, p. 43).

En la narración anterior se aprecia la forma en la que una persona conquistó de manera contundente a otras que se le acercaron, sin lugar a dudas la estrategia femenina utilizada se basó en su imagen y en las imágenes desatadas en la mente de los demás, pero... ¿qué es la imagen? Si nos atenemos a las etimologías, proviene del latín, imago (figura, imitación) y del griego, eikon (ícono, retrato).

Al respecto, Villafañe (2006) señala que la imagen forma parte de dos importantes procesos: la percepción y la representación. Por su parte, Costa (2004) sostiene que se define bajo dos sentidos principales: el primero, como objeto material y físico que se encuentra en todo lo que rodea al ser humano, y que se puede tocar de manera física; el segundo, como una representación mental, producto de la imaginación, es decir, aquello intangible. Por lo tanto, se tienen dos factores significativos: Io tangible (aquello que se toca de manera física) y lo intangible (aquello que no se toca más que por medio de una representación mental).

En cambio, Gordoa (2002) señala que la imagen es la percepción que inicia con una sensación interna, como resultado de una impresión que se da en los sentidos, es decir, se alude a una representación mental. Las definiciones anteriores pueden advertirse en el caso político Nixon-Kennedy, en 1960. Un debate político transmitido -por primera vez- por televisión, en donde los resultados de la proyección de la imagen fueron contundentes:

"Richard Nixon poseía una barba muy cerrada que pasadas las seis de la tarde daba a su rostro una sombra que connotaba cualidades negativas como maldad y 
suciedad [...] Por otro lado [...] el joven egresado de Harvard, eficiente, impecable y guapo, dueño de una seductora sonrisa y de una mirada encantadora" (p. 20).

Quienes escucharon el debate político por la radio dieron como ganador a Nixon y quienes lo vieron por televisión dieron a Kennedy el triunfo. Lo interesante en esta situación es apreciar que no sólo había ganado un joven a un experimentado político, sino que a través del análisis de la gestión de estímulos aplicados en eventos políticos (como un debate) y su transmisión por diferentes medios de comunicación, se identificaba una nueva manera de alcanzar metas y logros.

En medio de este escenario aparece lo que se denomina imagen pública. ¿Cómo se define? Gordoa (2002) advierte que se trata de la "percepción compartida que provoca una respuesta colectiva unificada" (p. 32). Lo cual significa que una percepción (sensación interna que queda en los sentidos ante una impresión) colectiva genera una respuesta que concuerda entre los miembros que perciben cierto evento o persona y, entonces, esa respuesta se convierte en una opinión que se da de manera uniforme. Por ejemplo: en un salón de clases en donde se encuentran cuarenta alumnos, si todos dicen que el profesor es excelente, la percepción colectiva da como resultado una respuesta que coincide entre sí y todos opinan que es excelente, entonces esa será su imagen pública.

\section{La percepción de las audiencias}

Abarca desde temas que son calificados por algunos como banales, como los colores que se utilizan en la indumentaria, accesorios, uso del maquillaje, corte de cabello, entre otros, hasta todo aquello que se asocia con protocolos y que tiene que ver con el trato que las personas o instituciones le dan a sus grupos objetivo, por nombrar algunos estímulos referentes con la imagen física -estímulos enviados por medio del lenguaje corporal y la apariencia de los individuos-. Esto es porque la imagen pública no abarca únicamente estímulos desde lo físico; las posibilidades de percepción se dan a través de una clasificación de seis imágenes a las que se les denomina imágenes subordinadas (Gordoa, 2002).

Dichas imágenes subordinadas son la imagen física, que se definió en líneas anteriores; la imagen profesional, que toma en cuenta estímulos observados en la práctica profesional, en donde el buen uso y gestión de protocolos permiten prevenir crisis o tener un plan estratégico para disminuirlas cuando se presentan; la imagen verbal o la percepción que los demás tienen de alguien, que se comunica a través de la expresión de la palabra verbal o escrita; la imagen visual, que se da a partir de los estímulos percibidos por medio de la vista, y en donde se considera la imagen que se proyecta o que perciben los grupos objetivo, por medio de signos y símbolos, por ejemplo, el mensaje que se proyecta a través de los colores y el tipo de letra de una tarjeta de presentación; la imagen audiovisual, que involucra estímulos percibidos con el sentido de la vista y el oído; y la imagen ambiental, la que transmite estímulos por medio de los escenarios de personas e instituciones. Por ejemplo, el mensaje que envía una oficina a través de su decoración. 
En este sentido, la coherencia es la actitud que le permite a una persona o institución ser percibida por los demás como consecuente, lógica y congruente con la toma de decisiones. Es un elemento valioso para la proyección de la imagen pública, pues se convierte en una ventaja competitiva, ya que una vez que las personas son percibidas como congruentes con lo que piensan, dicen y hacen, la aceptación entre sus audiencias es más probable que el rechazo.

La imagen pública tiene un patrón para generar coherencia: el estilo, definido como "la expresión de la individualidad" (Gordoa, 2002, p. 32), es decir, la manera en la que la esencia personal o institucional se expresa y forma parte de la respuesta a la pregunta: ¿quién soy? Es el ser antes que el parecer. La esencia es el fundamento de la imagen pública y es importante respetarla pues de no hacerse se caerá en la incongruencia y, por lo tanto, en el rechazo de las audiencias.

¿De dónde nace la teoría del estilo? A finales del siglo xx, dos consultoras en imagen, Alice Parsons y Diana Parente, la desarrollaron en su teoría Universal Style, que lo clasifica en: natural, tradicional, elegante, romántico, creativo, seductor y dramático. Cada uno de ellos proyecta un mensaje que genera fortalezas y riesgos. Ninguno es mejor que otro y para conocer el estilo que se proyecta es necesario aplicar una prueba que indica el principal para cada persona o institución. Una vez que se sabe el resultado será necesario delimitar cada una de las imágenes subordinadas para comunicar desde lo verbal y lo no verbal. De esta manera, dicho patrón funciona como una línea lógica que fusiona a cada imagen para lograr la coherencia.

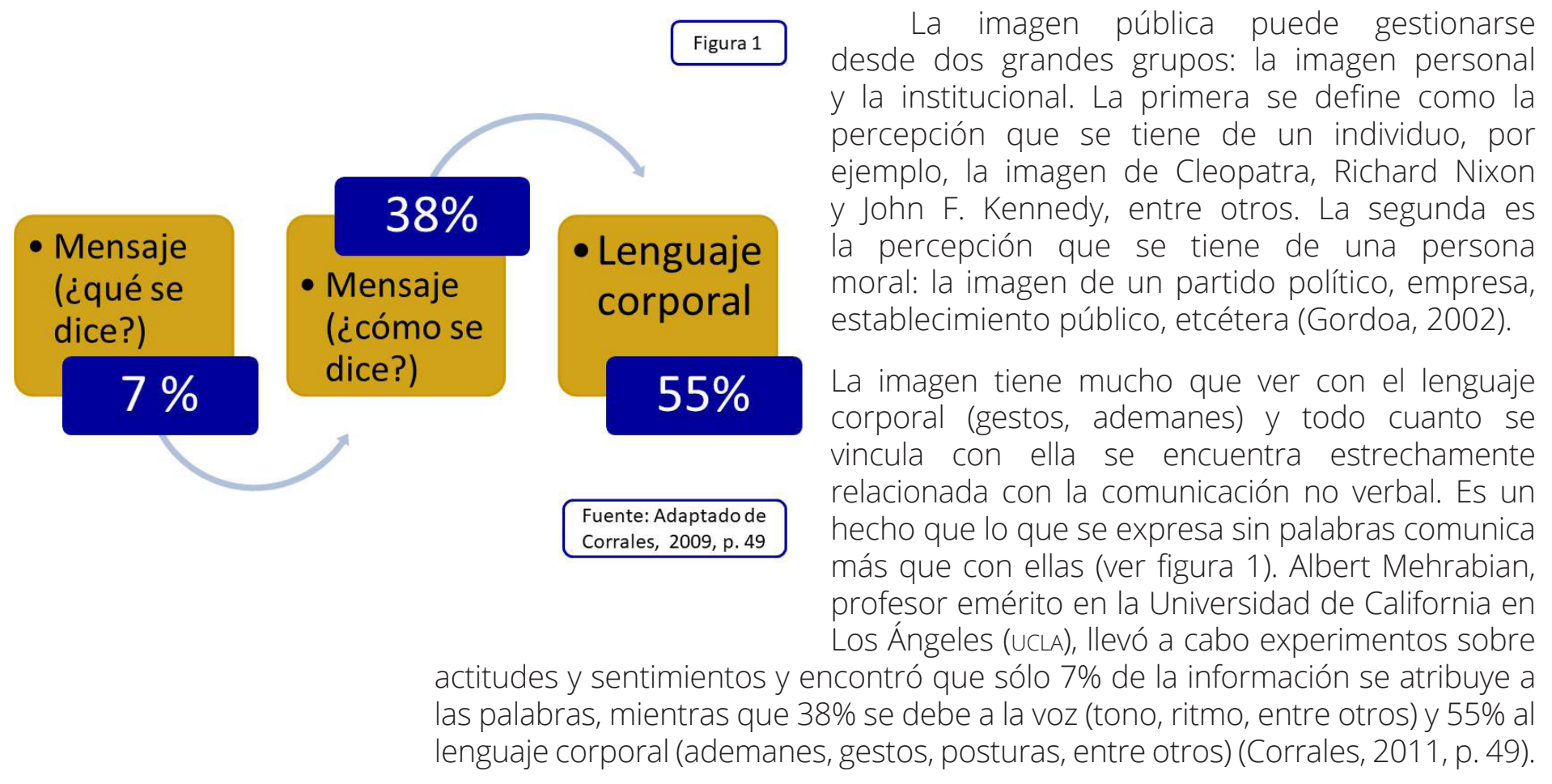




\section{Ecuación de la Imagen.}

Figura 2

\section{Estímulo +}

Receptor

De acuerdo con lo anterior, los seres humanos se comunican en un alto porcentaje (93\%) a partir de los estímulos identificados por medio de la comunicación no verbal. Gordoa (2002) sostiene que la percepción se da a partir de dos tipos de estímulos: verbales y no verbales. En los primeros tiene cabida todo aquello que las personas escriben y dicen (¿qué dice en su mensaje?); en los segundos, la manera en que lo hace forma parte de la comunicación no verbal (¿cómo dice su mensaje?), donde también se incluyen los factores de indumentaria, accesorios y lenguaje corporal.

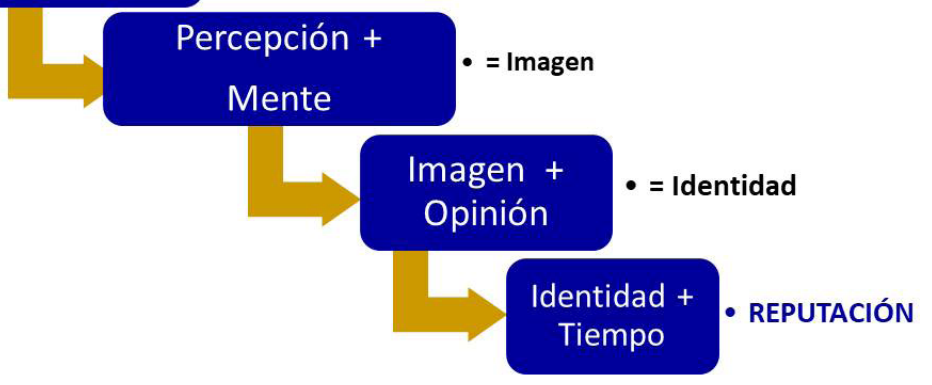

Fuente: Adaptado de Gordoa, 2002, p. 35
Uno de los aspectos más significativos de la imagen pública es la reputación. Es un intangible que se asocia con la actitud y la conducta, por lo que se comunica cuando los individuos se conducen de manera personal y profesional.

La ecuación de la imagen pública señala que ésta se da a partir de la opinión que identifica a las audiencias (identidad) y que se origina de una imagen formada desde de los estímulos percibidos, que se queda en la mente (ver figura 2). El objetivo del presente escrito es mostrar que la imagen pública tratada especialmente desde la imagen personal- se asocia con las representaciones mentales en donde los procesos de percepción y las áreas cerebrales que se activan, a partir de estímulos, se vinculan con la neurociencia social.

¿Por qué buscar la relación de la imagen pública con dichos temas? Porque su vínculo con estímulos no verbales la mantiene, en algunas ocasiones, en una posición superficial. No obstante, es importante reflexionar que los estímulos enviados desde detalles tan simples en apariencia tienen un sofisticado proceso asociado con la neurociencia social; por lo que cada elemento conlleva un impacto significativo entre las audiencias, debido a su relación con la toma de decisiones y la conformación de la reputación.

\section{La neurociencia social, la toma de decisiones y la reputación}

En las definiciones proporcionadas en anteriores párrafos se expuso que la imagen se deriva de la percepción y ésta de las representaciones mentales, por lo que la imagen tiene que ver con procesos cerebrales. De tal manera, no es casualidad que cursos como neuro-marketing, neuro-oratoria, neuro-ventas, neuro-diseño, entre otros, tengan un posicionamiento relevante en la mente de los consumidores, debido a que el prefijo neuro genera estatus, por su relación con el ansia de reconocimiento, prestigio, necesidad y el poder para explicar una 
diversidad de temáticas, sobre las cuales se tiene interés, pues se asocian con el éxito personal (Corredor y Cardenas, 2017).

¿Cuál es el origen de la neurociencia social? En la Antigüedad, el médico griego Galeno sostuvo que los procesos racionales se encontraban en el cerebro. En el siglo xIx, la publicación de ciertos casos clínicos asociados con el cerebro llamaron la atención con respecto a zonas específicas y su relación con la personalidad, las emociones y, en general, con el comportamiento social. Uno de los casos más peculiares es el de Phineas Gage, quien en 1848 sufrió un accidente cuando una carga de dinamita provocó que una barra de metal le atravesara su mejilla y cráneo, lo que dañó las zonas orbitofrontales y ventromediales de su cerebro. Posterior al accidente, su personalidad responsable y eficiente se modificó por la de una imagen caprichosa, irreverente y con un deficiente autogobierno de sus emociones (Grande-García, 2009).

Otros dos orígenes históricos fundamentales son la cognición social como parte importante de la psicología social y el desarrollo de la neurociencia cognitiva. La psicología social estudia la influencia de los factores socioculturales en la conducta. De ella se desprende la cognición social cuyos temas principales se asocian con la formación y modificación en la conducta, percepción social (percepción de las personas, formación de impresiones, representaciones y estereotipos), empatía, prejuicios, autoconocimiento, autoconcepto, autorregulación y el efecto que las emociones tienen sobre la conducta y la cognición (Grande-García, 2009).

Por otra parte, la neurociencia cognitiva involucra disciplinas relacionadas con la investigación cerebral, la biología molecular y la genética, así como la computación, que derivó hacia la neurociencia cognitiva. Además de lo anterior, para su estudio se agrega el análisis de la actividad cerebral bajo técnicas de neuroimagen y el registro de la actividad cerebral (Grande-García, 2009).

Es así como el desarrollo de la tecnología vinculada con la actividad cerebral y diversas técnicas de medición para entender los procesos psicosociales dieron paso a la neurociencia social. Pero... ¿cómo se define? La neurociencia social examina la manera en la que los sistemas nervioso, endocrino e inmune se relacionan con los procesos socioculturales, en una relación bidireccional entre el cerebro y los procesos sociales (Maneiro, 2017, p. 170). Es un campo interdisciplinario que vincula a las "técnicas de neuroimagen, neuropsicología, técnicas neuroquímicas, mediciones neuroinmunológicas, junto con la investigación en ciencias cognitivas y en ciencias sociales como la psicología social, la economía y las ciencias políticas" (Grande-García, 2009, p. 2).

Se trata de ver cómo influye en el cerebro lo que pasa en la vida social y cómo lo que pasa en la vida social afecta al cerebro. Es así como la imagen pública se asocia con la neurociencia social al tener en cada experiencia personal un bagaje de estímulos que se convierten en imágenes mentales. Los ejemplos relatados en el inicio del artículo sobre Cleopatra y el debate político entre 
Nixon y Kennedy permiten observar el efecto de los estímulos en las imágenes mentales.

Uno de esos efectos es lo que se denomina primera impresión, el impacto de la imagen que se proyecta en un primer encuentro y que se queda como una marca en la mente de los demás. Es un proceso cerebral que interpreta los códigos de los estímulos en unos cuantos segundos (Gordoa, 2002). De manera inconsciente se pone en marcha todo un proceso que activa zonas cerebrales y con el que se evalúa a los demás y que permite definir el gusto o no por las personas o las situaciones; de esta manera, las primeras impresiones se asocian con la reputación.

Como ya se comentó en líneas anteriores, uno de los grandes temas que se resalta en la imagen pública (tal como se puede ver en la figura 2) es la reputación, la toma de decisiones basada en ella es un ejemplo de la forma en la que la imagen pública tiene un vínculo significativo con la neurociencia social. El caso de Phineas Gage es un ejemplo en el que se observa la modificación de su imagen personal (y de su reputación), proyectada a partir de la toma de decisiones que se vieron afectadas por cambios en sus procesos cerebrales después de un accidente. El caso señala la relación bidireccional entre los procesos cerebrales y los sociales.

Antes de revisar los mecanismos neurales que participan en esta relación se debe responder a la pregunta: ¿qué es la reputación y por qué es tan anhelada por las personas? Pérez y Rodríguez (2014) la entienden como un intangible difícil de copiar, por lo que saber gestionarla permite obtener importantes ventajas competitivas, que pueden mantenerse a través del tiempo.

En cambio, Post y Griffin la definen como un compendio de percepciones y opiniones de los grupos objetivo de una organización (empleados, clientes, proveedores y en general la comunidad vinculada con dicha organización) (Martínez y Olmedo, 2010). Mientras que Gordoa (2002) señala que es la imagen sostenida en el tiempo.

¿Por qué es tan importante? Porque cuando una persona o empresa la gestiona es más fácil posicionarse en la mente de sus audiencias y obtener ventajas competitivas, que los mantiene como líder en los ámbitos en donde se desenvuelve, lo que conduce a la obtención de ciertos beneficios para la imagen personal: las propuestas ofrecidas son aceptadas fácilmente, o una mejor paga por los servicios y productos que se ofrecen. Las personas valoran y reconocen a quienes se han preocupado por cuidar y gestionar su imagen pública. Es una moneda de cambio que se construye día con día porque cuando la gente tiene contacto con ella de inmediato la evalúa y si le parece valiosa se asocia para gozar de dicha reputación. ¿A quién no le gustaría colaborar con una persona con una reputación coherente? 


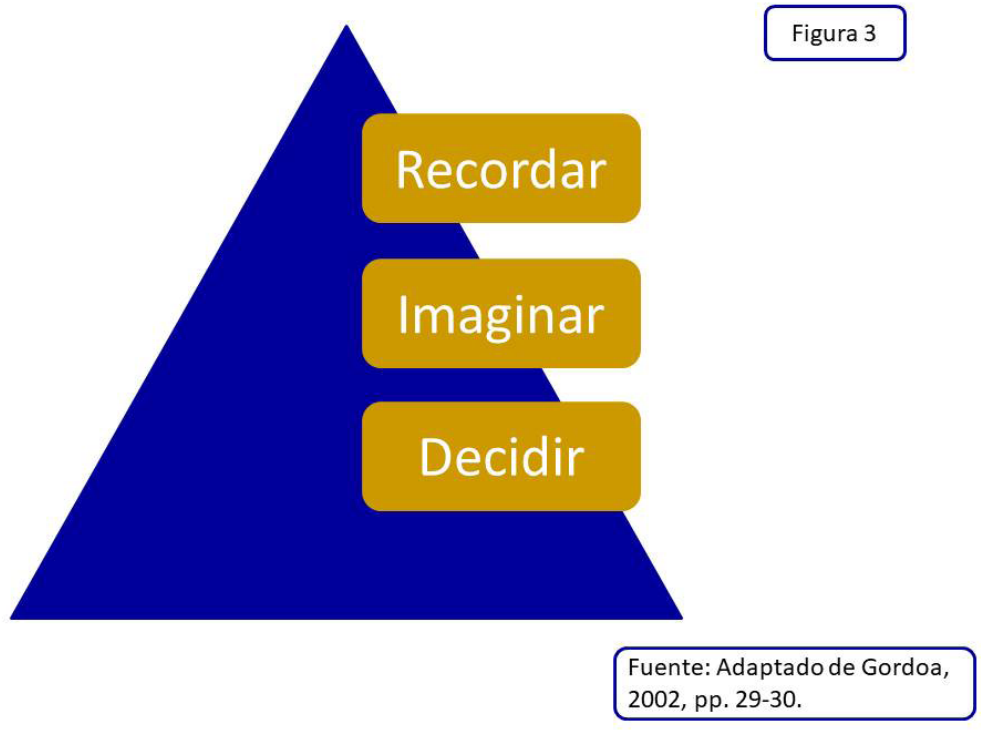

Lo anterior puede resumirse en que la reputación genera una imagen pública atractiva ante la percepción de las audiencias, pues la confianza y la seguridad personal despiertan un sentimiento de credibilidad, de aceptación y de inspiración. Es importante resaltar que la imagen pública se aplica bajo su condición de imagen mental, lo cual tiene que ver con el proceso de la percepción, en donde los estímulos (verbales y no verbales) son captados por los sentidos para transportarse a través del sistema nervioso central y así arribar al cerebro en donde la información se procesa.

Se explica fácil, sin embargo, se trata de un proceso sofisticado en donde las imágenes mentales afectan a las personas desde tres aspectos diferentes (ver figura 3):

1. Recordar: las imágenes percibidas se quedan grabadas en la memoria para poder echar mano de ellas en el momento que se les requiera.

2. Imaginar: la mente procesa la información percibida y tiene la capacidad de asociar ideas y crearlas para elaborar imágenes.

3. Las imágenes recordadas y/o imaginadas afectan las conductas y preferencias de los seres humanos, por lo tanto, también la toma de decisiones y, en consecuencia, la reputación (Gordoa, 2002).

Es importante que las personas tomen en cuenta que la imagen es inevitable y que se da bajo un proceso cerebral a través del cual los mensajes de los estímulos se interpretan en unos cuantos segundos (Gordoa, 2002). Hablen o no hablen con sus grupos objetivo, los atiendan con amabilidad o no, se vistan de traje o de mezclilla, las audiencias siempre tendrán una imagen de una primera impresión porque la estarán percibiendo. En este proceso de percepción aparecen en escena mecanismos neurales.

Izuma (2012) sostiene que la toma de decisiones basada en la reputación implica ciertas recompensas e involucra procesos cognitivos complejos, que sólo pueden darse en la comunicación entre los seres humanos, debido a que requiere de metarrepresentaciones (pensar sobre el pensar, por ejemplo: ¿qué pensará el lector sobre mi artículo? ¿Le interesará o no?, es decir, la escritora piensa sobre lo que el lector puede pensar sobre ella). También se necesita de la evaluación costo-beneficio en el cual se revisa si la recompensa -a partir de cierta decisión- generará una reputación positiva.

El estriado y la corteza prefrontal media son zonas cerebrales que participan de manera significativa en la toma de decisiones basadas en la reputación. El estriado se asocia con el proceso de recompensas y también se estimula cuando 
los individuos son agradables ante los demás. Por su parte, la corteza prefrontal media tiene un papel fundamental para mantener metas y manipular a los demás con respecto a sus opiniones sobre la propia persona (Izuma, 2012) (ver figura 4).

La reputación se conecta con los procesos de percepción social y la autorregulación, en donde se involucra la captación de señales en el ambiente. Aquí se hace presente la amígdala, ya que procesa la importancia emocional o social de los estímulos, misma que se activa con los ojos. En este sentido, la mirada resulta un estímulo potente para inducir hacia conductas prosociales.

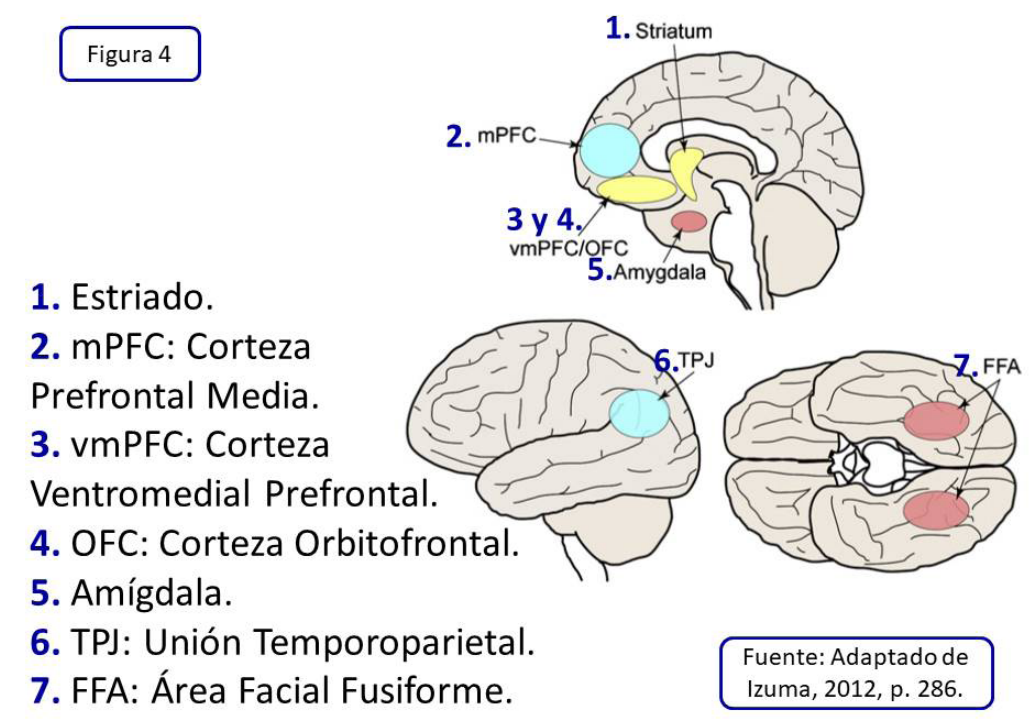

Algunas otras zonas que se activan en la toma de decisiones basadas en la reputación son la corteza visual temporal, "que participa en la detección de estímulos sociales (por ejemplo: la presencia de otras personas, la dirección de la mirada)" (p. 285). La corteza ventromedial prefrontal y la corteza orbitofrontal, analizan el costobeneficio de las acciones y participan en el proceso de recompensas. El área facial fusiforme (FFA) es la zona que decodifica la identidad del rostro; mientras que la corteza prefrontal media y la unión temporoparietal se vinculan con la formación de metarrepresentaciones. El autocontrol o autorregulación se activa en la corteza dorsolateral prefrontal (Izuma, 2012).

La amígdala que capta las emociones de los estímulos tiene un papel importante en la proyección de la imagen porque"la mente decide mayoritariamente basada en sentimientos" (Gordoa, 2002, p. 41). Muchas veces la reputación se ve afectada por la toma de decisiones por su vínculo con las imágenes mentales y por los sentimientos y emociones que lleva consigo. Por eso se debe hacer consciencia de que las personas con una reputación sobresaliente no la obtienen con ciertas pócimas mágicas. Tener una reputación significativa, relacionada con la toma de decisiones y acciones coherentes, se asocia con un autoconocimiento y un autogobierno emocional que, además, tiene mucho que ver con la activación de zonas cerebrales, como las mencionadas con anterioridad. 
En el siguiente video se puede observar la manera en la que algunas zonas cerebrales intervienen en la imagen de una pareja y de cómo la toma de decisiones (dadas con las metarrepresentaciones que permiten la visualización de una nueva relación) permea en la reputación (cuando se obtienen recompensas con la sortija que el novio le da a la novia).

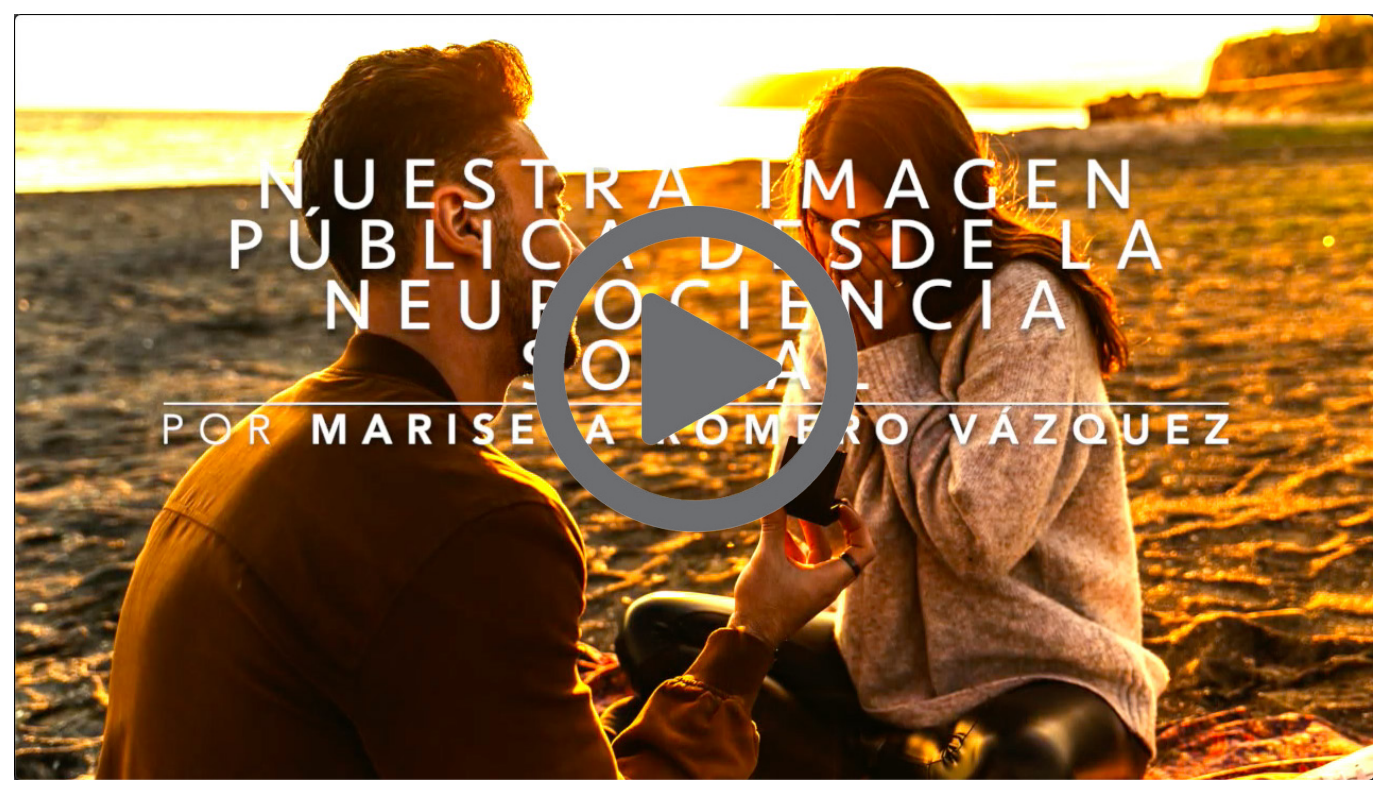

Pese a que la reputación puede sostener la imagen pública en el tiempo, se debe tomar en cuenta que ésta se encuentra limitada y no todos son sensibles a ella. Las personas con autismo, esquizofrenia o fobia social no tendrán el comportamiento esperado a partir de factores que incrementen la reputación (Izuma, 2012). Lo interesante es que la imagen pública está delimitada por el contexto personal que incluye:

1. Rasgos genéticos, biológicos y fisiológicos, que influyen en la proyección de una imagen definida por características propias e innatas de la persona.

Algunas de ellas podrían no percibirse a primera vista, por ejemplo, la estrategia de una persona daltónica para conducir un automóvil será aprenderse el orden de los colores de un semáforo, no obstante, cuando por alguna razón este orden se modifica, un accidente puede ser la causa de que las personas opinen que tal vez el conductor se encontraba bajo el influjo del alcohol o concentrado en su teléfono celular, pero nunca pensarán que dicho incidente se debió a un rasgo genético del conductor, por lo que la proyección de su imagen entre los individuos que observaron el accidente puede interpretarse como negativa.

2. La situación sociocultural, en donde aparecen hábitos y tradiciones compartidos que involucran a cierta historia colectiva. 
Las personas proyectan su imagen con rasgos aprendidos desde su historia colectiva bajo un determinado contexto social y cultural que, al mismo tiempo, se encuentra permeado por signos y símbolos que proyectan una imagen, de aquí las diferencias entre conductas formadas bajo diferentes contextos. Por ejemplo, en la Ciudad de México se tiene la creencia de que se debe mirar a los ojos a la gente con autoridad para enviarle el mensaje de que se le reconoce su jerarquía y se le respeta. No obstante en otras culturas, como en la japonesa, no mirar de frente comunica respeto hacia las personas con autoridad. Una persona de origen japonés que no mira de frente a otra mexicana puede ser percibida bajo una actitud irrespetuosa o insolente, cuando en realidad es lo contrario.

3. La historia personal (con su pasado, su presente y las expectativas para el futuro): se refiere a las singularidades individuales de cada persona.

Por ejemplo, alguien que en su infancia vivió pobreza extrema y que en su presente experimenta un momento económico favorable estará ahorrando para darse un viaje por Europa, por lo que no aceptará salir con amigos, ir a fiestas y a reuniones. Sus amigos probablemente opinarán que no le gusta ser sociable por no aceptar las invitaciones y por no divertirse, lo que puede generar rechazo entre sus audiencias más cercanas. Lo que sus allegados no saben es la razón de su pasado, la oportunidad de su presente y la expectativa (con un anhelo vehemente) de su viaje en un futuro (Gubern, 2007).

Es decir, en la proyección e interpretación de la imagen pública se deben tomar en cuenta los aspectos antes descritos, pues de esta manera los individuos pueden tener una autorregulación que posibilite primeras impresiones que permitan la comprensión y empatía de actitudes no esperadas o que podrían tomarse como negativas.

\section{Conclusiones}

El tema de la imagen pública debe tratarse desde un enfoque mental, el cual se construye bajo un proceso complejo asociado con la activación de diversas zonas cerebrales vistas desde la neurociencia social. Esta disciplina se vincula a su vez con un campo interdisciplinario en donde los procesos sociales tienen influencia en el cerebro y viceversa. Es un camino de doble vía.

La toma de decisiones se encuentra asociada con la reputación y ésta con la imagen pública. Las personas estarán evaluando en todo momento dichas decisiones y se emitirá una opinión que con el tiempo se traducirá en la reputación. Entonces, si la toma de decisiones se percibe como coherente, la reputación también lo será, y aparecerán ventajas competitivas y beneficios. En cambio, si se percibe incongruente se generará rechazo. 
El estudio de la toma de decisiones basada en la reputación permite describir la manera en la que los procesos cerebrales interfieren para generar imágenes mentales. Por ello, es importante que las personas tomen consciencia de los estímulos que envían ante sus audiencias más cercanas (familia, amigos, jefes, directores, entre otros); pues debido a esa estimulación los demás interpretan su imagen personal como adecuada o inadecuada, la rechazan o la aceptan.

Así, se debe estar conscientes de lo siguiente: nuestra imagen pública debe ser trabajada por medio de procesos estratégicos para conquistar objetivos. Es decir, hay que analizar y gestionar los estímulos que se desean propiciar para alcanzar metas. Ya que nuestra imagen pública se procesa en la mente de los demás, es mucho mejor trabajarla de manera consciente y responsable para no dejar que los otros lo hagan por nosotros.

Al mismo tiempo, se debe considerar que nuestra imagen pública, más que superficial o banal, tiene una raíz sofisticada con fundamentos en la neurociencia social. De igual manera, tener en cuenta que al ser un camino de doble vía, la proyección de dicha imagen puede no ser lo que "normalmente" se espera, porque las zonas cerebrales se activan bajo rasgos genéticos, biológicos, situaciones socioculturales y asociadas con la historia de vida personal. Es decir, la imagen que se esperaría de una persona puede no coincidir con la que se expresa, por lo que no sobra contar con una actitud empática y comprensiva de lo que se percibe.

Con todo lo anterior, ¿estás consciente de ello apreciado lector?

\section{Referencias}

* Álvarez del Blanco, R. (2008). Tú Marca Personal: gestiona tu vida con talento y conviértela en una experiencia única. Prentice Hall.

* Corrales Navarro, E. (enero-junio, 2011). El lenguaje no verbal: un proceso cognitivo superior indispensable para el ser humano. Revista Comunicación, 20(1), 46-51. http://www.redalyc.org/pdf/166/16620943007.pdf.

* Corredor, K. y Cárdenas, F. P. (2017, mayo-agosto). Neuro-<lo que sea>: inicio y auge de una pseudociencia para el siglo xxı. Revista Latinoamericana de Psicología, 49(2), 89-90. Recuperado de https://www.redalyc.org/pdf/805/80551191001.pdf.

* Costa, J. (2004). La imagen de marca: un fenómeno social. Paidós Ibérica.

* Gordoa, V. (2002). El poder de la imagen pública. Edamex.

* Gordoa, V. (2003). Imagología. Grijalbo. 
* Grande-García, I. (junio, 2009). Neurociencia social: el maridaje entre la psicología social y las neurociencias cognitivas. Revisión e introducción a una nueva disciplina. Anales de psicología, 25(1), 1-20. http://www.um.es/analesps/v25/v25 1/01-25_1. pdf.

* Greene, R. (2001). El arte de la seducción. Océano.

* Gubern, R. (2007). Del bisonte a la realidad virtual: la escena y el laberinto (4a. ed.). Anagrama.

Izuma, K. (abril, 2012). The social neuroscience of reputation. Neuroscience research, 72, 283-288.

* Maneiro Crespo, E. (2017). Neurociencia y emociones: nuevas posibilidades en el estudio del comportamiento político. RIPS. Revista de Investigaciones Políticas y Sociológicas, 16(1), 169-187. http://www.redalyc.org/pdf/380/38051452008.pdf.

* Martínez, I. y Olmedo, I. (septiembre, 2010). Revisión teórica de la reputación en el entorno empresarial. Cuadernos de economía y dirección de empresa, 44, 59-77. https://www.researchgate.net/publication/49598460 Revision teorica de la reputacion en el entorno empresarial

* Pérez, A. y Rodríguez del Bosque, I. (2014, enero-junio). Identidad, imagen y reputación de la empresa: integración de propuestas teóricas para una gestión exitosa. Cuadernos de Gestión, 14(1), 97-126. http://www.redalyc.org/ pdf/2743/274330593005.pdf.

* Ponce Mejía, T. (2012). Fundamentos psicopedagógicos. Red Tercer Milenio

* Ramos Linares, V., Rivero Burón, R., Piqueras Rodríguez, J. A., García López, L. J. y Oblitas Guadalupe, L. A. (2008, marzo). Psiconeuroinmunología: conexiones entre sistema nervioso y sistema inmune. Suma psicológica, 15(1), 115-141.

* Villafañe, J. (2006). Introducción a la teoría de la imagen. Pirámide.

\section{Glosario}

Banal: de poca importancia.

Conducta pro-social: aquella que beneficia a los demás con consecuencias sociales positivas y que incluyen la solidaridad, la cooperación y el altruismo.

Audiencias: grupo de personas al que va dirigida la imagen que se proyecta.

Estímulo: impulso para provocar una acción.

Intangible: aquello que no se toca más que por medio de una representación mental.

Metarrepresentación: representación de lo que las personas piensan de otras, también se le puede definir como pensar sobre el pensar. 
Prejuicio: opinión que se da antes de conocer el contexto de los hechos.

Protocolo: conjunto de reglas, rituales y ceremoniales establecidas por costumbre (Gordoa, 2002).

Representación mental: imagen que vuelve a estar presente y que se activa con estímulos internos (signos y símbolos) y externos (el contexto).

Reputación: imagen sostenida en el tiempo (Gordoa, 2002).

Sistema inmune: el que identifica y excluye sustancias que le son extrañas al organismo como virus, bacterias, hongos y parásitos (Ramos, Rivero, Piqueras, García y Oblitas, 2008).

Sistema endocrino: el que se encarga de segregar hormonas.

Sistema nervioso: el que coordina las funciones conscientes e inconscientes y está formado por el sistema nervioso central y el sistema nervioso periférico (Ponce, 2012).

Superficial: sin fundamento y que se basa en apariencias.

Ventaja competitiva: característica que genera diferencias de unas personas con otras, lo cual permite mejorías y un posicionamiento superior en el mercado.

\section{Cómo citar este artículo}

* Romero Vázquez, Marisela. (2020). Nuestra imagen pública desde la neurociencia social. Revista Digital Universitaria (RDU) Vol. 21, núm. 3 mayo-junio. Dol: http://doi. org/10.22201/codeic.16076079e.2020.v21n3.a5.

Recepción: 03/01/2019. Aceptación: 19/11/2019. 